Article

\title{
Adsorption and Flame Retardant Properties of Bio-Based Phytic Acid on Wool Fabric
}

\author{
Xian-Wei Cheng, Jin-Ping Guan, Guoqiang Chen, Xu-Hong Yang * and Ren-Cheng Tang * \\ National Engineering Laboratory for Modern Silk, College of Textile and Clothing Engineering, \\ Soochow University, 199 Renai Road, Suzhou 215123, China; chengxian-wei@outlook.com (X.-W.C.); \\ guanjinping@suda.edu.cn (J.-P.G.); chenguojiang@suda.edu.cn (G.C.) \\ * Correspondence: yangxuhong@suda.edu.cn (X.-H.Y.); tangrencheng@suda.edu.cn (R.-C.T.); \\ Tel.: +86-512-6716-4993 (X.-H.Y. \& R.-C.T.); Fax: +86-512-6724-6786 (X.-H.Y. \& R.-C.T.)
}

Academic Editor: Baljinder Kandola

Received: 25 February 2016; Accepted: 30 March 2016; Published: 5 April 2016

\begin{abstract}
Bio-based phytic acid (PA) as a nontoxic naturally occurring compound is a promising prospect for flame-retardant (FR) modifications to polymers. In this work, PA was applied to wool fabric using an exhaustion technique, and the adsorption and FR properties of PA on wool fabric were studied. The flame retardancy of the treated wool fabrics depended greatly on the adsorption quantity of $\mathrm{PA}$, which was related to the $\mathrm{pH}$ of treatment solution, immersing temperature and initial PA concentration. The Langmuir adsorption of PA took place due to electrostatic interactions between PA and wool fiber. The limiting oxygen index, vertical burning and pyrolysis combustion flow calorimetry tests revealed that the treated wool fabrics exhibited good flame retardancy. The measurements of the phosphorus content of the burned fabric residues and thermogravimetric analyses suggested that a significant condensed-phase FR action was applicable to the PA treated fabrics. PA treatment was found to have little adverse effect on the whiteness and mechanical performance of wool. Additionally, the washing resistance of the FR fabrics should be further improved.
\end{abstract}

Keywords: wool; phytic acid; adsorption; flame retardant; burning behavior

\section{Introduction}

As a natural protein fiber, wool is widely used in apparel, interior textiles and industrial clothing for its comfort and a high level of inherent flame resistance. The inherent flame-resistant properties of wool are related to its relatively high nitrogen $(15 \%-16 \%)$ and sulfur $(3 \%-4 \%)$ content, high moisture content $(10 \%-14 \%)$ and low heat of combustion $[1,2]$. However, most wool fabrics can pass a horizontal test but cannot pass $45^{\circ}$ or vertical tests. Some special products such as seat coverings in cars and buses, aircraft furnishings and blankets, wall coverings in public buildings, protective clothing, and carpets of shag pile construction and low density need additional treatment to impart higher flame resistance [3].

The Zirpro flame retardant (FR) treatment, which can markedly improve the flame resistance of wool, are based on the exhaustion of negatively charged zirconium or titanium complexes onto positively charged wool under acid conditions [4,5]. The Zirpro treatment has become the most commonly used durable FR process for wool [6]. Based on the Zirpro process, many kinds of acids such as formic acid and hydrochloric acid have been applied along with zirconium or titanium complexes to improve the FR properties of wool fabrics [7-10]. Some intumescent agents such as tetrakis-hydroxymethyl phosphonium condensates (THPC), N-methylol dimethyl phosphonopropionamide derivatives (MDPA) and simple ammonium phosphates have also been applied to increase the FR properties of wool fabric by means of the formation of a high thermal 
resistance insulation char layer [11-13]. Other approaches have been used to enhance the FR properties of wool [14,15]. As a whole, though, little has changed since 1986, when Horrocks comprehensively discussed the development of flame retardants for wool [9,11].

Considering the cons of the flame retardants used, the USA and EU directives concerning the chemistry of flame retardants are becoming increasingly rigid and severe, so some of the currently used products will be limited or even banned. Therefore, both the academic and industrial communities should continuously invest time and funds in order to find worthy alternatives to traditional flame retardants. In this context, very recently, some biomacromolecules like proteins and nucleic acids have been thoroughly investigated because they exhibit significant potentials as novel green FRs for selected textiles [16]. For example, caseins, hydrophobins, whey proteins and deoxyribonucleic acid have been successfully applied to improve the FR properties of cotton fabrics by padding techniques [17-20]. In addition, caseins have been found to be efficient for the improvement of the FR capability of polyester and polyester/cotton blends [21].

Recently, a bio-based phosphorus-containing compound phytic acid (PA) has provoked people's interest in textile treatment, especially in FR treatment. PA is known as inositol hexakisphosphate acid or phytate in the salt form, and regarded as a "green" molecule because it is found in abundance in plants tissues, such as beans, cereal grains and oil seeds [22,23]. As a biocompatible, environmentally friendly, nontoxic and easily obtained organic acid [24,25], PA has already been widely applied in antioxidant, anticancer, biosensor, cation exchange, nanomaterial and other fields because of its special inositol hexaphosphate structure [26]. PA contains $28 \mathrm{wt} \%$ phosphorus based upon molecular weight, and is promising as one of possible and effective FR materials. PA has been used to reduce the flammability of cellulose-based materials. PA has been employed as a doping acid to greatly improve the FR performance of polyaniline-deposited paper composite [27]. PA/chitosan and $\mathrm{PA} /$ nitrogen-modified silane hybrids have been used via layer-by-layer assembly to fabricate FR thin films on cotton fabric $[26,28]$. In addition, the potential FR effect of different metallic phytates has been evaluated as bio-sourced phosphorus additives for poly(lactic acid) composites [29].

PA consists of six negatively charged phosphate groups and has a strong tendency to combine or interact with positively charged metal ions or proteins [30,31]. This means it is possible that PA can combine with wool fiber (natural protein fiber) by means of the electrostatic interaction between the positively charged amino groups in wool and the negatively phosphate groups in PA. In the work reported here, PA was applied to wool fabric through an exhaustion process with the aim of improving the flame resistance of woolen textiles. The important factors affecting the adsorption of PA such as $\mathrm{pH}$, temperature and PA concentration were discussed. The combustion and thermal properties of the treated fabrics were evaluated via limiting oxygen index (LOI), vertical burning test, pyrolysis combustion flow calorimetry (PCFC) and thermogravimetry (TG). Scanning electron microscopy (SEM) coupled with energy dispersive X-ray spectroscopy (EDS) was used to investigate the morphology of the treated fibers. Furthermore, the phosphorus content of the unburned and burned wool fabrics was detected by inductively coupled plasma optical emission spectrometry (ICP-OES).

\section{Materials and Methods}

\subsection{Materials}

The scoured, woven wool fabric (warp and weft thread, $156 \mathrm{dtex} \times 2$ ) for color fastness tests up to the standard GB/T 7568.1-2002 was purchased from Shanghai Textile Industry Institute (Shanghai, China) of Technical Supervision. Phytic acid (PA) (70\% aqueous solution) of analytical reagent grade was obtained from the Chengdu Ai Keda Chemical Technology Co. Ltd., Chengdu, China. Sodium hydroxide of analytical reagent grade was purchased from Sinopharm Chemical Reagent Shanghai Co. Ltd., Shanghai, China. 


\subsection{Experiments of the Adsorption of $P A$}

All of the adsorption and treatment experiments of PA were carried out in the sealed and conical flasks immersed in a XW-ZDR low-noise oscillated dyeing machine (Jiangsu Jingiiang Xingwang Dyeing and Finishing Machinery Factory, Jingjiang, China). The liquor ratio was 50:1. At the end of processing, the wool fabrics were washed in distilled water and then dried in the open air.

\subsubsection{Effect of $\mathrm{pH}$ on the Adsorption of PA}

The $\mathrm{pH}$ of PA solutions was adjusted to 1.2, 2.1, 3.0 and 4.1 by addition of $1 \mathrm{M}$ sodium hydroxide solution and detected by a PHS-3C pH meter (Shanghai REX Instrument Factory, Shanghai, China). The wool fabrics were immersed in the solutions of $120 \%$ owf (on the weight of fiber) PA at $30^{\circ} \mathrm{C}$, and the temperature was raised to $90{ }^{\circ} \mathrm{C}$ at a rate of $2{ }^{\circ} \mathrm{C} / \mathrm{min}$ and the treatment continued for $60 \mathrm{~min}$.

\subsubsection{Effect of Temperature on the Adsorption of PA}

To assess the effect of immersing temperature on the adsorption of PA, wool fabrics were treated with the solutions of $120 \%$ owf PA for which the $\mathrm{pH}$ was adjusted to 1.2. The samples were immersed into the solutions at $30^{\circ} \mathrm{C}$, and the temperature was raised to different temperatures $\left(50-98^{\circ} \mathrm{C}\right.$ ) at a rate of $2{ }^{\circ} \mathrm{C} / \mathrm{min}$ with a holding time of $60 \mathrm{~min}$.

\subsubsection{Equilibrium Adsorption Isotherm of PA}

The adsorption isotherm of PA on wool fabric was measured in a series of PA solutions of various concentrations $(10 \%-200 \%$ owf $)$ at $90{ }^{\circ} \mathrm{C}$ with the $\mathrm{pH}$ adjusted to 1.2 . The isotherm was determined on the basis of the adsorption for $100 \mathrm{~min}$ as the tests showed that the equilibrium adsorption was reached in $60 \mathrm{~min}$.

\subsubsection{Building-up Property of PA}

The building-up property of PA on wool fabric was measured in the solutions $(\mathrm{pH} 1.2)$ of $10 \%-200 \%$ owf PA. The fabrics were immersed in the solutions at $30^{\circ} \mathrm{C}$, and subsequently the solutions were heated to $90{ }^{\circ} \mathrm{C}$ at a rate of $2{ }^{\circ} \mathrm{C} / \mathrm{min}$ and the treatment continued for $60 \mathrm{~min}$.

\subsection{FR Treatment of Wool Fabric}

In the adsorption experiments described above, a small-scale sample of $1 \mathrm{~g}$ and a high liquor ratio of 50:1 were used for the purposes of the convenience and accuracy of this study. However, the samples with large areas were needed for the investigations on the FR and physical properties of wool, so a sample of $8 \mathrm{~g}$ and a low liquor ratio of 15:1 were employed to carry out the FR treatment. The other processing parameters used this treatment were the same as those in Section 2.2.4. The samples so obtained were used for the flame retardancy research. In particular, Wool-0, Wool-40, Wool-80 and Wool-120 mentioned in the results and discussion section represent the fabrics treated with $0 \%, 40 \%$, $80 \%$ and $120 \%$ owf PA, respectively, and their corresponding weight gain was $0 \%, 10.6 \%, 15.0 \%$ and $17.9 \%$, respectively.

\subsection{Measurements}

\subsubsection{Adsorptions of PA}

The absorption spectra and absorbance $\left(\lambda_{\max }=261 \mathrm{~nm}\right)$ of PA solutions were measured using a Shimadzu UV-1800 UV-Vis spectrophotometer (Shimadzu Co., Kyoto, Japan). Using a previously established absorbance and concentration relationship at the $\lambda_{\max }$ of the PA solution, the quantity of PA in solution was able to be calculated, and the percentage of exhaustion was determined using Equation (1), where $m_{0}$ and $m_{1}$ are the quantities of PA in solution before and after treatment, 
respectively. The quantity of PA on wool was calculated by the difference in the initial and final concentrations of PA in solution.

$$
\text { Exhaustion }(\%)=100 \times\left(m_{0}-m_{1}\right) / m_{0}
$$

\subsubsection{Weight Gain}

The fabrics before and after treatment were dried in an oven at $60^{\circ} \mathrm{C}$ for $30 \mathrm{~min}$, and then weighed quickly. The weight gain of the treated fabric was calculated using Equation (2).

$$
\text { Weight gain }(\%)=100 \times\left(W_{2}-W_{1}\right) / W_{1}
$$

where $W_{1}$ and $W_{2}$ are the weights of the fabrics before and after treatment, respectively.

\subsubsection{LOI Test}

The LOI values of the fabrics were measured according to GB/T 5454-1997 (equivalent to ASTM Standard Method D2863) with the FTT0080 oxygen index apparatus (Fire Testing Technology Ltd., East Grinstead, UK).

\subsubsection{Vertical Burning Test}

The vertical burning test was conducted according to GB/T 5455-2014 (equivalent to ASTM Standard Method D6413) with the YG 815B automatic vertical flammability cabinet (Ningbo Textile Instrument Factory, Ningbo, China). The burning behavior of the fabrics for the vertical burning test was classified according to GB 8624-2012.

\subsubsection{PCFC Test}

The PCFC analysis was conducted using the FTT0001 microscale combustion calorimetry (Fire Testing Technology Ltd., East Grinstead, UK) according to ASTM Standard Method D7309. About $5 \mathrm{mg}$ specimen was thermally decomposed in an oxygenated environment at a constant heating rate of $1^{\circ} \mathrm{C} / \mathrm{s}$.

\subsubsection{TG Analysis}

The thermogravimetric (TG) curves were recorded with the Diamond TG/DTA SII thermal analyzer (Perkin-Elmer, Waltham, MA, USA) from 30 to $700{ }^{\circ} \mathrm{C}$ at the scan rate of $10^{\circ} \mathrm{C} / \mathrm{min}$ under a flow of air $(20 \mathrm{~mL} / \mathrm{min})$. Each sample was controlled to $4-5 \mathrm{mg}$ in primary weight.

\subsubsection{FT-IR Spectra}

The Fourier transform infrared (FT-IR) spectra of wool samples were measured by the Nicolet 5700 FT-IR spectrometer (Thermo Fisher Scientific Inc., Waltham, MA, USA) over the wavenumber range of $4000-400 \mathrm{~cm}^{-1}$ using $\mathrm{KBr}$ pellets. All of the IR data were collected from 32 scans with a resolution of $4.0 \mathrm{~cm}^{-1}$.

\subsubsection{SEM Observation}

The wool fibers as well as the chars obtained in the PCFC experiments were first sputter-coated with a gold layer, and then their surface morphologies were observed by a TM3030 tabletop scanning electron microscope (Hitachi High Technologies America, Inc., Schaumburg, IL, USA) with a $15 \mathrm{kV}$ accelerated voltage. The phosphorus content was tested by EDS with a $15 \mathrm{kV}$ electron beam energy. 


\subsubsection{ICP-OES}

The phosphorus content of the unburned and burned wool fabrics was measured as follows: the dried fabric and char residue $(0.1 \mathrm{~g})$ were digested in $30 \mathrm{~mL}$ of $15 \mathrm{wt} \%$ nitric acid for $2 \mathrm{~h}$ at $80{ }^{\circ} \mathrm{C}$. A phosphorus standard solution was used for calibration, and the digestion solutions were diluted to be in the calibration range prior to analysis. ICP-OES was conducted on the ICAP 6300 DUO (Thermo Fisher Scientific Inc., Waltham, MA, USA) with argon plasma at the wavelength of $178.284 \mathrm{~nm}$. The P content was calculated by Equation (3).

$$
\text { P content }(\mathrm{mg} / \mathrm{g})=\frac{C_{s}}{W} \times V
$$

where $C_{\mathrm{s}}$ is the P concentration in the digestion solution analyzed by ICP-OES $(\mathrm{mg} / \mathrm{L}) ; V$ is the volume of the digestion solution $(0.03 \mathrm{~L}) ; \mathrm{W}$ is the weight of the dried sample $(0.1 \mathrm{~g})$.

\subsubsection{Whiteness Index}

The whiteness of wool fabrics was measured with the WSB-2 digital whiteness meter (Shanghai Pingxuan Scientific Instrument Co. Ltd., Shanghai, China) in accordance with ASTM Standard Method E313. Each sample was tested four times at different positions and the average of the data was used.

\subsubsection{Mechanical Performance}

The tensile strength of wool fabrics was measured according to ISO 13934-1-2013 with the Instron 3365 tester (Illinois Tool Works Inc., HighWycombe, Buckinghamshire, UK). For each sample, five test specimens were tested and the stress-strain plot that represents the average result was reported. The samples were conditioned under a standard atmospheric condition $(65 \% \pm 5 \%$ relative humidity and $21 \pm 1^{\circ} \mathrm{C}$ ) for $24 \mathrm{~h}$ before testing.

\subsubsection{Durability to Washing}

The washing test of the treated wool fabric was carried out in the pots housed in a WashTec-P fastness tester (Roaches International, WestYorkshire, UK). The washing solution contained $4 \mathrm{~g} / \mathrm{L}$ commercial detergent, and the liquor ratio was 50:1. Each wash was conducted at $40{ }^{\circ} \mathrm{C}$ for $5 \mathrm{~min}$. After one wash, the fabric was removed, gently squeezed, and rinsed with tap water. Then repeated washing was carried out until a total of 250 min was reached.

\section{Results and Discussion}

\subsection{Adsorption Properties of PA}

\subsubsection{Effect of $\mathrm{pH}$ on the Uptake of PA}

The exhaustion of PA at different $\mathrm{pH}$ values was tested and the results are shown in Figure 1. The adsorption of PA on wool fiber was found to be sensitive to $\mathrm{pH}$. The exhaustion decreased obviously with increasing $\mathrm{pH}$ in the range of 1.2-4.1. This indicates that the electrostatic interactions between the positively charged amino groups in wool fiber and the anionic phosphate groups in PA exert an important role in the adsorption of PA on wool. The higher extent of adsorption at pH 1.2 is due to the greater protonation extent of amino groups which gives rise to ion-ion interaction. As the quantity of the protonated amino groups in wool fiber was greatly reduced at $\mathrm{pH} 4.1$, the exhaustion of PA on wool fiber became quite low. This implies that non-electrostatic interactions between PA and wool fiber are fairly small. 


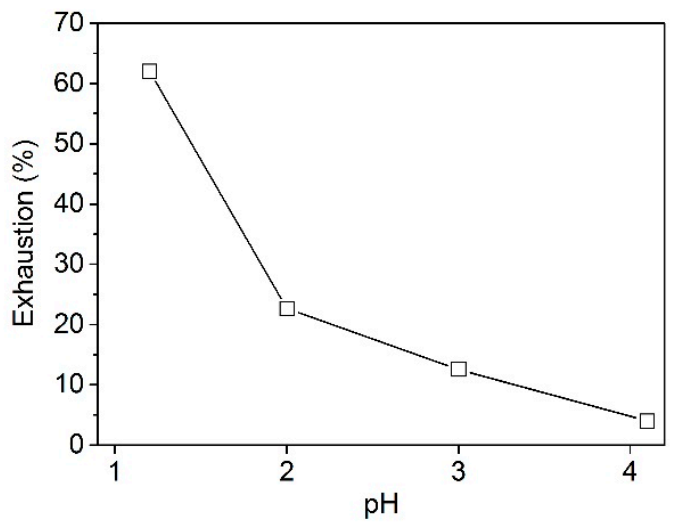

Figure 1. Effect of $\mathrm{pH}$ on the uptake of PA by wool.

\subsubsection{Effect of Temperature on the Uptake of PA}

Wool is a natural protein fiber and its surface is covered by cuticles which can reduce the rate of small molecules (e.g., dyes) entering the fiber interior. Because a high temperature can increase the swelling extent of wool fiber, temperature is an important parameter during the wet processing of wool. The uptake of PA by wool at different temperatures is shown in Figure 2. A small exhaustion was found at $50{ }^{\circ} \mathrm{C}$, this being attributed to the surface barrier action of the cuticle layer to PA penetration into fiber interior. The exhaustion increased with increasing temperature because high temperature can increase the swelling degree of wool fiber and thus promote the diffusion of PA into fiber interior. As a result, an immersing temperature of $90{ }^{\circ} \mathrm{C}$ was needed to ensure the higher adsorption of PA by wool.

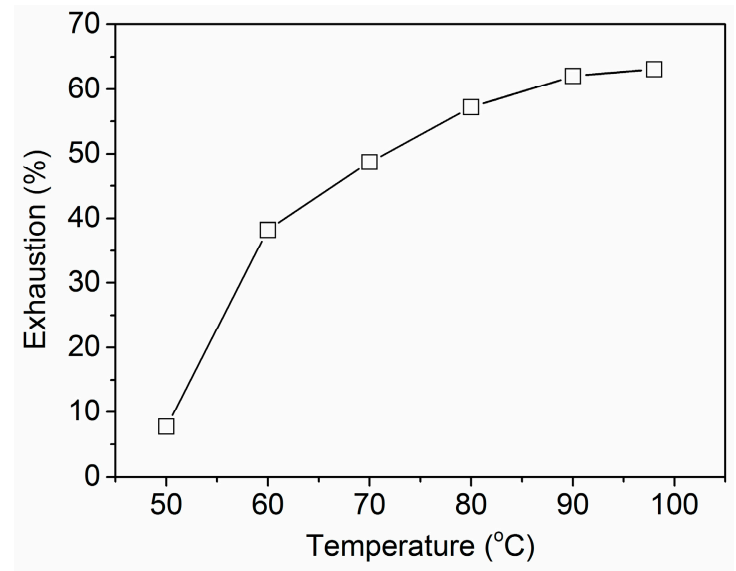

Figure 2. Effect of temperature on the uptake of PA by wool.

\subsubsection{Equilibrium Adsorption Isotherm of PA}

The equilibrium adsorption isotherm of PA on wool fiber can be depicted by the plot of the concentration of PA on wool fiber $\left(C_{\mathrm{f}}, \mathrm{g} / \mathrm{g}\right)$ as a function of the concentration of PA in solution $\left(C_{\mathrm{s}}, \mathrm{g} / \mathrm{L}\right)$ at equilibrium. The effect of initial PA concentration on equilibrium adsorption was evaluated within the range of $10 \%-200 \%$ owf. As shown in Figure 3a, with an increase in the initial concentration of PA, there was an increase in adsorption capacity until equilibrium was attained. 

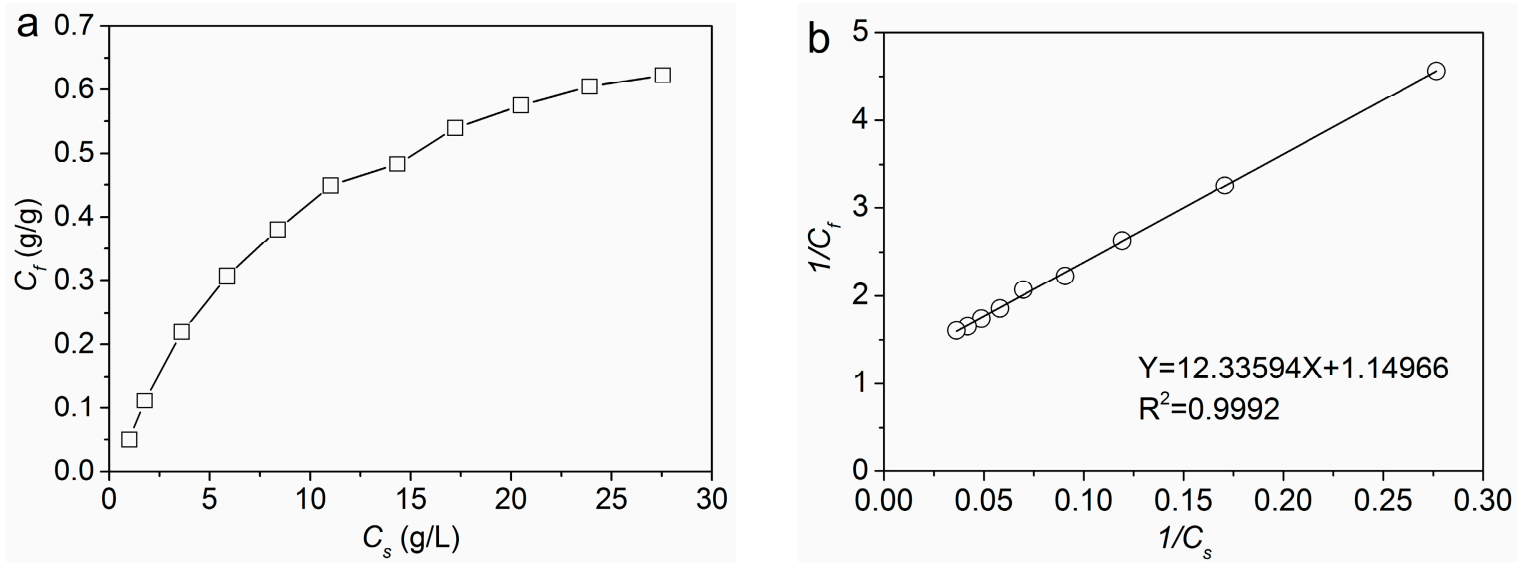

Figure 3. Adsorption isotherm of PA on wool: (a) plot of $C_{\mathrm{f}}$ vs. $C_{\mathrm{s}}$ and (b) plot of $1 / C_{\mathrm{f}} v \mathrm{~s} .1 / C_{\mathrm{s}}$.

The experimental data were fitted to the following Langmiur equation:

$$
C_{\mathrm{f}}=\frac{S K C_{s}}{1+K C_{s}}
$$

where $S$ is the saturation concentration of PA on wool fiber, and $\mathrm{K}$ is the Langmuir affinity constant.

The Langmuir isotherm plot of $1 / C_{\mathrm{f}}$ vs. $1 / C_{\mathrm{s}}$ is shown in Figure $3 \mathrm{~b}$. The Langmuir equation exhibited a high correlation $\left(R^{2}=0.9992\right)$ to the experimental data, indicating that the Langmuir isotherm is an appropriate model to describe the adsorption behavior of PA on wool fiber. The saturation of PA adsorption on wool fiber was $0.8792 \mathrm{~g} / \mathrm{g}$ and the Langmuir affinity constant was $0.0932 \mathrm{~L} / \mathrm{g}$. It can therefore be concluded that electrostatic interactions occur between the anionic PA molecules and the protonated amino groups in wool fiber.

\subsubsection{Building-up Property of PA}

The building-up property of PA depends on its affinity to wool fiber and its adsorption saturation, which is of great importance for practical application. Considering practical application conditions, the building-up property of PA was determined in a temperature-rise process in place of a constant temperature employed for the adsorption isotherm studies. The building-up property of PA expressed by the exhaustion as well as the quantity of PA absorbed by wool $\left(C_{\mathrm{f}}\right)$ is depicted in Figure 4 . The quantity of adsorption linearly increased with increasing PA concentration in the range of $10 \%-140 \%$ owf, indicating a good building-up property of PA on wool fiber. Figure 4 also reveals that the lower exhaustion was obtained as the application concentration of PA increased, but the exhaustion was still higher than $60 \%$ at a PA dosage of $120 \%$ owf. The results indicate that PA has a fairly high utilization rate. 


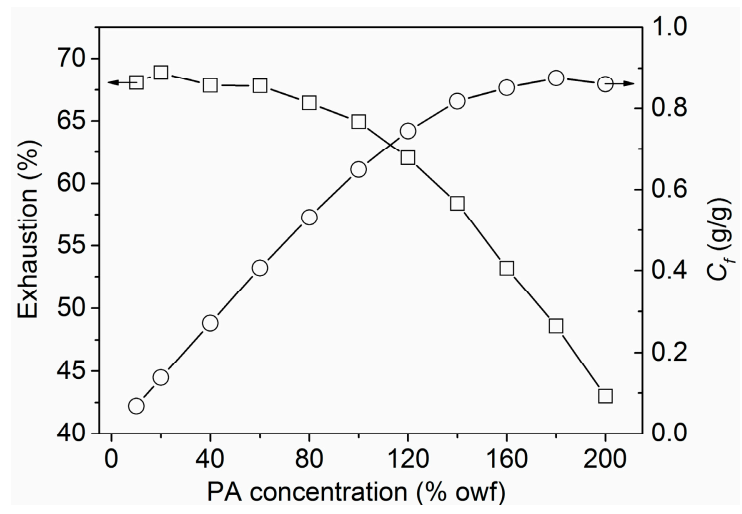

Figure 4. Influence of initial PA concentration on its uptake by wool.

\subsection{Flame Retardancy}

\subsubsection{Flammability Test}

LOI and vertical burning tests are widely used to determine the relative flammability of polymeric materials. The LOI and weight gain of the wool fabrics treated with PA solutions of different concentrations are shown in Figure 5. Clearly, the higher weight gain and LOI of the fabrics were obtained when a higher PA concentration was used. The flame retardancy of the treated wool fabrics also showed a linear relationship with the content of PA on fiber substrate. The untreated wool fabric had a low LOI of $23.6 \%$. When treated with $140 \%$ owf PA, the wool fabric experienced a weight gain of $17.9 \%$ and exhibited a very high LOI of $35.2 \%$.

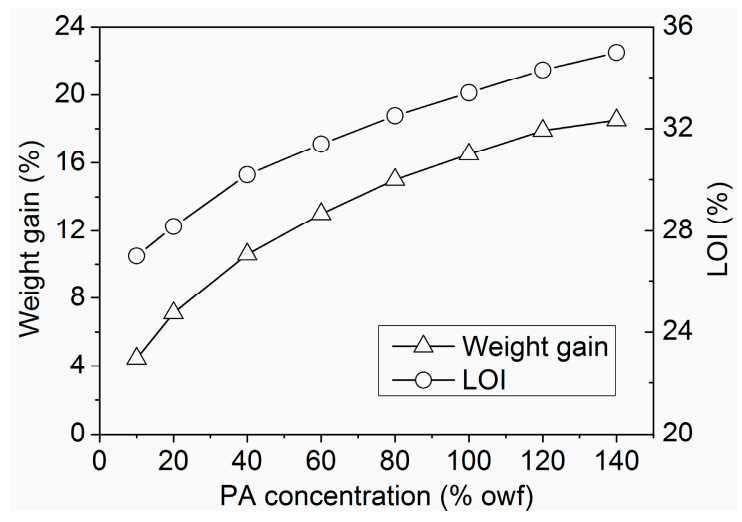

Figure 5. Weight gain and LOI of the wool fabrics treated with PA.

There are three different classifications of FR fabrics based on the vertical burning test according to GB 8624-2012: (1) $B_{1}$ classification: char length $\leqslant 15 \mathrm{~cm}$, after flame time $\leqslant 5 \mathrm{~s}$, after glow time $\leqslant 15 \mathrm{~s}$; (2) $B_{2}$ classification: char length $\leqslant 20 \mathrm{~cm}$, after flame time $\leqslant 15 \mathrm{~s}$, after glow time $\leqslant 30 \mathrm{~s}$; and (3) $B_{3}$ classification: no special requirement. The untreated wool fabric had a very high combustion speed, and it was completely burned out. Figure 6a shows the char length of the wool fabrics treated with PA, and Figure $6 \mathrm{~b}$ displays the photographs of the burned fabrics whose char length approaches the calculated average value. PA could effectively strengthen the char formation ability of wool fabric. The inflated char could successfully withstand the open fire below and prevent neighboring polymeric substrate from further attack by heat flux, so the treated wool fabrics with good flame retardancy are self-extinguished after the removal of ignition source. As shown in Figure 6, the char length of the fabrics treated with PA decreased obviously. More than $20 \%$ owf of PA could endow wool fabric with 
a $B_{1}$ classification according to the vertical burning test. The aforementioned results indicate that PA can significantly improve the flame retardancy of wool fabric.

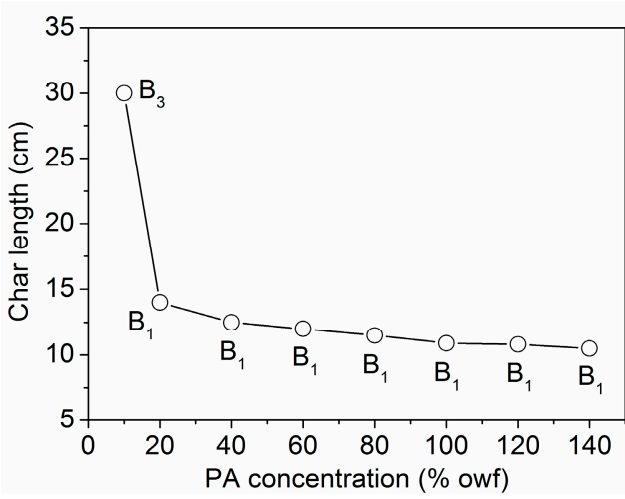

(a)

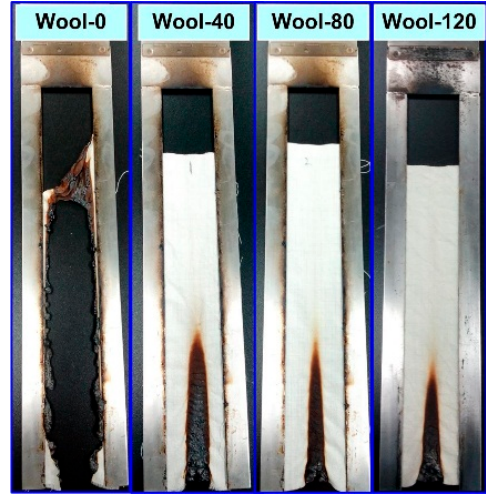

(b)

Figure 6. Char length (a) and photographs (b) of the treated wool fabrics after vertical burning tests.

\subsubsection{PCFC Analyses}

As a supplement to LOI and vertical burning tests, the PCFC test is an effective analytical technique for measuring the flammability of milligram-sized materials and screening new FR agents [32]. Although PCFC as a milligram-scale test cannot replace flame and fire tests, it has been shown to be correlated with the data from some fire tests [32]. So the PCFC test was employed to evaluate the FR behavior of the treated wool fabric by measuring the heat release rate (HRR), peak heat release rate ( $\mathrm{pHRR}$ in $\mathrm{W} / \mathrm{g}$ ), heat release capacity (HRC in J/(g K)), total heat release (THR in $\mathrm{kJ} / \mathrm{g}$ ) and temperature at maximum heat release rate $\left(T_{\max }\right)$.

The pHRR is an important parameter to evaluate the intensity of combustion. Figure 7 shows the HRR curves of the wool fabrics treated with PA. The corresponding combustion data are listed in Table 1. It is evident that the pHRR values of the treated wool fabrics were much lower than that of pure wool fabric, and decreased with increasing PA concentration. The untreated fabric had a high pHRR value of $131.7 \mathrm{~W} / \mathrm{g}$. As for Wool-40, Wool-80 and Wool-120, the pHRR decreased to 89.8, 80.7 and $76.7 \mathrm{~W} / \mathrm{g}$, which were $31.8 \%, 38.7 \%$ and $41.7 \%$ reduction, respectively. HRC is a relatively good predictor of heat release rate in flaming combustion. As shown in Table 1, the treated wool fabrics had much lower HRC values than pure wool, and the HRC value decreased further with increasing PA concentration. THR calculated from the total area under the HRR peaks is another important parameter for fire hazard evaluation [33]. THR showed the same trend as PHRR and HRC. In addition, the $T_{\max }$ values of the treated wool fabrics decreased compared to pure wool possibly because of the lower initial thermal stability of PA. The PCFC data presented here convincingly demonstrate that the treated wool fabrics possess low flammability, indicating the effectiveness of PA as a FR agent on wool fiber.

From the PCFC test, the information about the charring of wool fabrics can also be obtained. The morphological structures and P content of the char residues obtained in this test were discussed in Sections 3.2.5 and 3.2.6. 


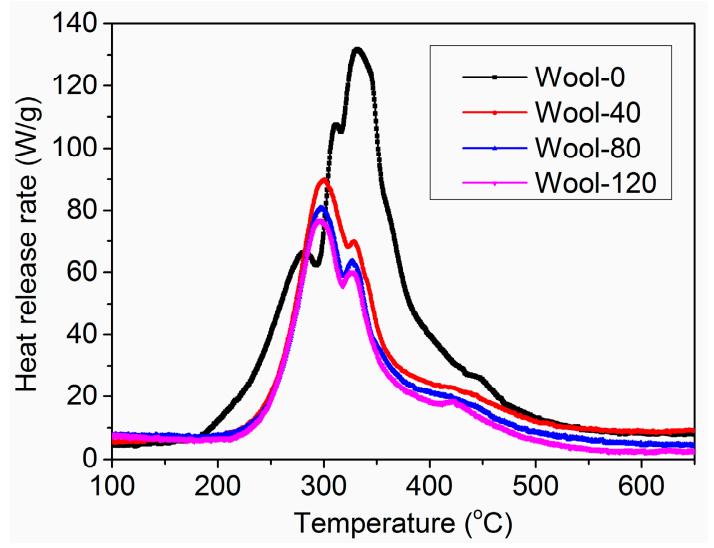

Figure 7. HRR curves of the wool fabrics from the PCFC test.

Table 1. PCFC parameters for the wool fabrics treated with PA.

\begin{tabular}{ccccc}
\hline Samples & HRC $(\mathbf{J} /(\mathbf{g}$ K)) & pHRR $(\mathbf{W} / \mathbf{g})$ & THR $(\mathbf{k J} / \mathrm{g})$ & $\boldsymbol{T}_{\max }\left({ }^{\circ} \mathbf{C}\right)$ \\
\hline Wool-0 & $130 \pm 4$ & $131.7 \pm 3.5$ & $14.0 \pm 0.5$ & $331.7 \pm 3.4$ \\
Wool-40 & $85 \pm 1$ & $89.8 \pm 1.9$ & $8.2 \pm 0.1$ & $300.3 \pm 0.5$ \\
Wool-80 & $78 \pm 2$ & $80.7 \pm 0.4$ & $7.4 \pm 0.2$ & $296.6 \pm 0.5$ \\
Wool-120 & $74 \pm 2$ & $76.7 \pm 1.6$ & $6.7 \pm 0.2$ & $296.1 \pm 2.7$ \\
\hline
\end{tabular}

\subsubsection{TG Analyses}

The thermogravimetric (TG) and derivative theremogravimetric (DTG) curves under air and nitrogen were used to study the thermal degradation and stability of wool fabrics. The TG and DTG curves of the samples and the calculated TG curve of Wool-120 are shown in Figure 8. The related thermal decomposition data are listed in Table 2, where $T_{20 \%}$ and $T_{50 \%}$ are defined as the temperatures corresponding to a weight loss of $20 \%$ and $50 \%$, respectively.

Table 2. TG data of wool fabrics under air and nitrogen.

\begin{tabular}{cccccc}
\hline \multirow{2}{*}{ Samples } & \multirow{2}{*}{$\mathbf{T}_{\mathbf{2 0} \%}\left({ }^{\circ} \mathbf{C}\right)$} & $\boldsymbol{T}_{\mathbf{5 0} \%}\left({ }^{\circ} \mathbf{C}\right)$ & \multicolumn{2}{c}{ Char Residues at $\mathbf{7 0 0}{ }^{\circ} \mathbf{C ~ ( \% )}$} \\
\cline { 5 - 6 } & & & & Experimental & Calculated \\
\hline \multirow{6}{*}{ Air } & PA & 132.9 & 543.8 & 20.6 & - \\
& Wool-0 & 270.0 & 399.9 & 2.8 & 2.8 \\
& Wool-40 & 278.3 & 453.9 & 26.1 & 4.6 \\
& Wool-80 & 277.8 & 459.6 & 31.5 & 5.1 \\
& Wool-120 & 279.8 & 478.1 & 36.0 & 5.5 \\
\hline \multirow{6}{*}{ Nitrogen } & PA & 145.4 & 543.2 & 26.3 & - \\
& Wool-0 & 264.9 & 343.7 & 22.3 & 22.3 \\
& Wool-40 & 270.6 & 357.6 & 33.2 & 24.7 \\
& Wool-80 & 274.8 & 386.9 & 37.6 & 24.5 \\
\hline
\end{tabular}



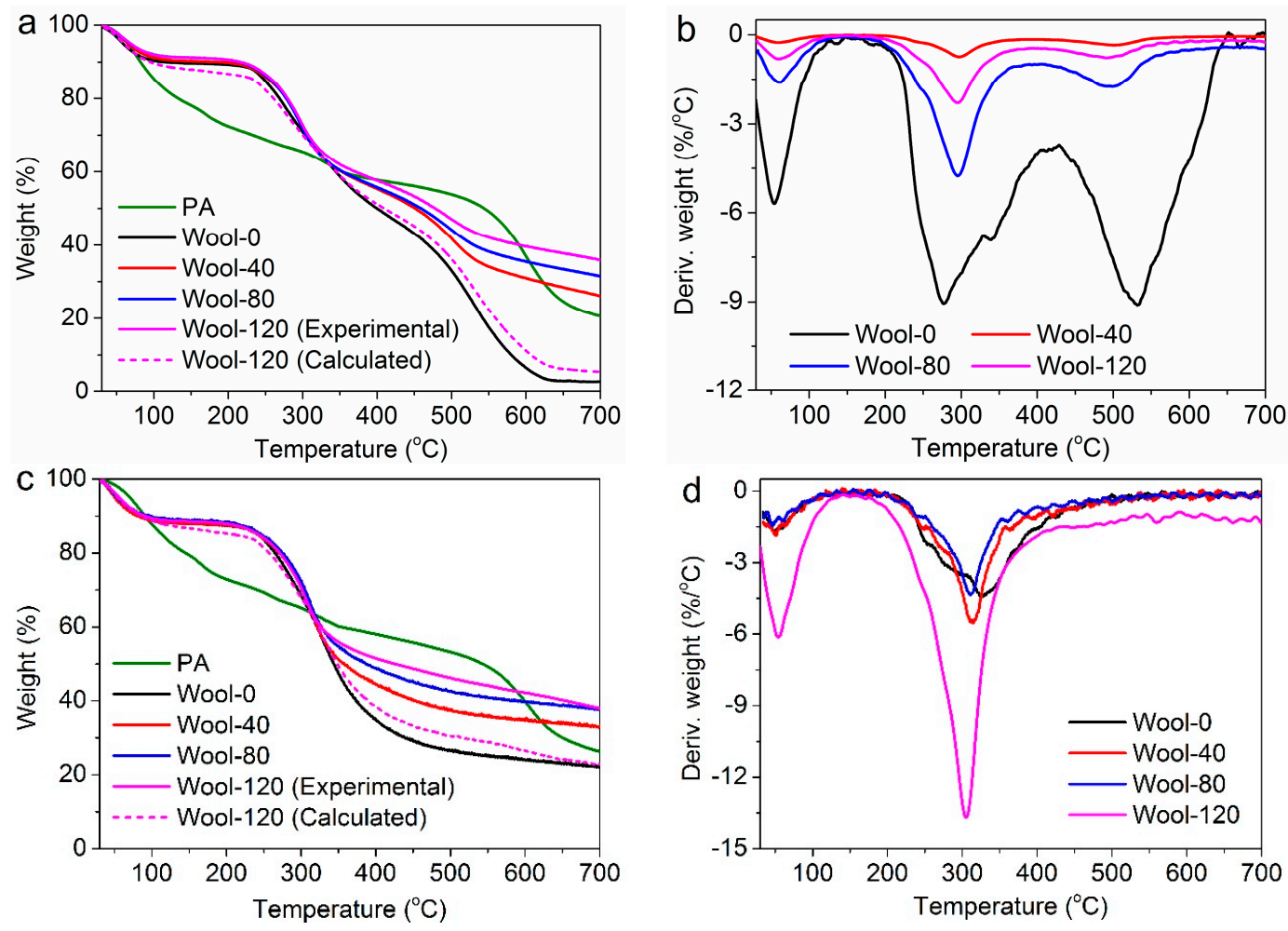

Figure 8. TG and DTG curves of wool fabrics under air $(\mathbf{a}, \mathbf{b})$ and nitrogen $(\mathbf{c}, \mathbf{d})$.

As stated in previous reports, three processes take place during the wool pyrolysis process under air $[9,10,12]$. From Figure $8 b$, the first process was observed from 30 to $160{ }^{\circ} \mathrm{C}$, corresponding with the desorption of water physically bound to wool fiber and the dehydration of wool fiber. The second process occurred from 190 to $425^{\circ} \mathrm{C}$, coinciding with the temperature range over which a number of defined pyrolysis reactions take place in wool. At the second stage, the hydrogen-bond peptide helical structure ruptures and the ordered regions of wool fiber undergo a solid-to-liquid phase change; also, the cleavage of the disulphide bonds occurs and a number of volatiles including hydrogen sulfide and sulphur dioxide are released. The third process is dominated by the char oxidation reactions. At this process, the char and remaining hydrocarbon species were further oxidized to carbon monoxide and carbon dioxide. However, Figure $8 \mathrm{c}$,d show that the thermal degradation of wool under nitrogen proceeded only in two steps, during which the further char oxidation process might be not involved.

Compared to wool, PA exhibited higher weight loss at low temperature, and lower weight loss at high temperature. The adsorbed PA by wool is responsible for an obvious increase in the decomposition temperature of wool, as revealed by the $T_{20 \%}$ and $T_{50 \%}$ in Table 2 and well demonstrated by Figure 8 . This indicates that the introduction of PA changes the decomposition behavior of wool, and enhances the thermal stability of wool. Assuming that no chemical or physical interactions between wool and PA occur, the calculated TG curve of Wool-120 was able to be obtained on the basis of the simply additive contribution of wool and PA. The experimental and calculated TG curves of Wool-120 did not overlap as shown in Figure 8a,c, and the experimental curve exhibited much higher residues compared to the calculated one. This observation reveals that some interactions between wool and PA chains take place during the heating, and the degradation of PA interferes with the degradation reactions of wool. Compared to $2.8 \%$ char residue for Wool- 0 at $700{ }^{\circ} \mathrm{C}$ under air, the char residues of Wool-40, Wool-80 and Wool-120 were $26.1 \%, 31.5 \%$ and $36.0 \%$, respectively. The similar trend for char residues was found in the case of nitrogen atmosphere. Such high char residues of the FR fabrics indicate the high thermal insulation of the char and the good resistance of char to the aforementioned 
oxidation reactions. This also implies that the FR mechanism of the treated wool involves a significant condensed-phase activity.

\subsubsection{FT-IR Analyses}

The FT-IR spectrum of PA is shown in Figure 9a. The strong peak around $3490 \mathrm{~cm}^{-1}$ belongs to the $\mathrm{OH}$ stretching vibration of PA. The peak at $1635 \mathrm{~cm}^{-1}$ is caused by the hydration of water molecules [34]. The broad peak between 1210 and $945 \mathrm{~cm}^{-1}$ is associated with the stretching vibration of $\mathrm{P}=\mathrm{O}, \mathrm{O}-\mathrm{P}-\mathrm{C}, \mathrm{P}-\mathrm{O}$ and $\mathrm{O}-\mathrm{P}-\mathrm{O}$ structures [34-36]. The FT-IR spectra of the treated and untreated wool fabrics are shown in Figure $9 \mathrm{~b}$. The peaks around 1635 and $1520 \mathrm{~cm}^{-1}$ are the characteristic bands of amide I ( $\mathrm{C}=\mathrm{O}$ stretching) and amide II ( $\mathrm{N}-\mathrm{H}$ bending and $\mathrm{C}-\mathrm{H}$ stretching) for wool fiber, respectively. The characteristics of the amide I band are associated with the $\mathrm{C}=\mathrm{O}$ stretching of $\alpha$-helix, $\beta$-sheet and random disorder secondary structures of keratin [37]. In the spectrum of the treated wool, the new peaks at 1168 and $1060 \mathrm{~cm}^{-1}$ are due to the stretching vibration of $\mathrm{P}=\mathrm{O}$ and $\mathrm{O}-\mathrm{P}-\mathrm{C}$ structure [34-36], respectively. These results showed that the treated wool fibers contain $\mathrm{P}=\mathrm{O}$ and $\mathrm{P}-\mathrm{O}-\mathrm{C}$ structures, which are helpful to improve the flame retardancy of the fabric.
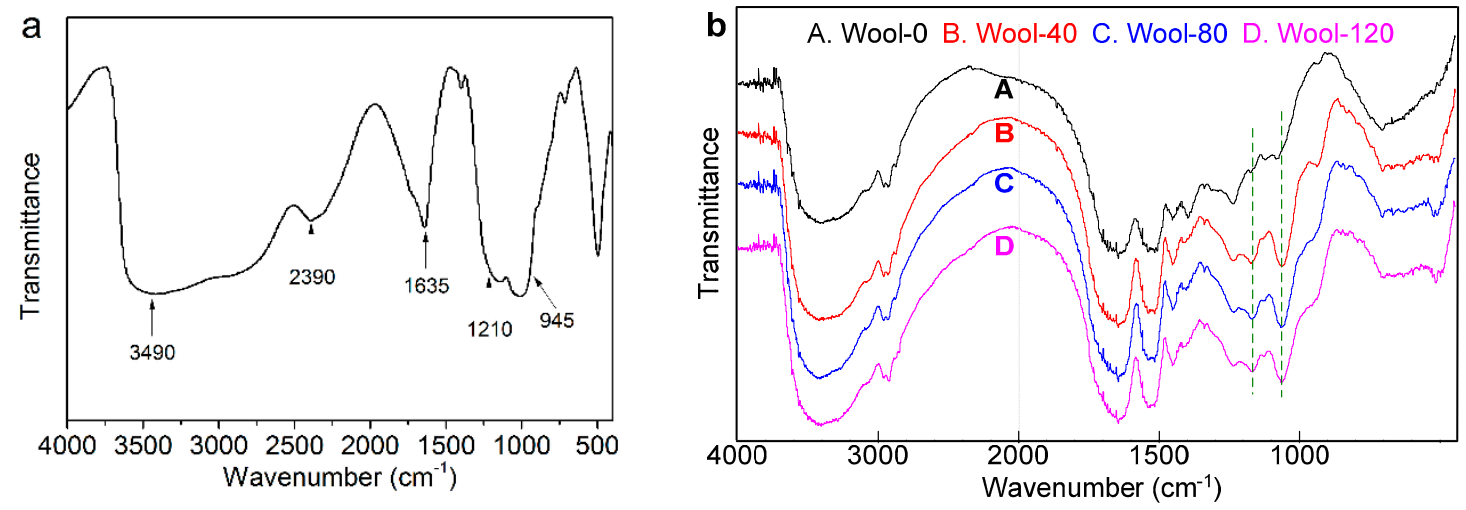

Figure 9. FT-IR spectra of (a) PA and (b) wool fabrics.

\subsubsection{SEM Analyses}

SEM was employed to study the morphological structures of wool fibers and char residues. Figure 10 shows the SEM micrographs of the wool fibers and corresponding char residues after the PCFC test. The untreated wool displayed the clean scales on its surface. The low magnification micrographs (Figure 10a) showed that PA did not accumulate within the fabric texture. From the high magnification micrographs (Figure 10b), a handful of particles were found to be attached to the surfaces of the treated wool fibers. After the FR treatment, most loose chemicals on the fiber surface should be washed off by the rinsing process. Only a handful of PA depositions on the fiber surface prove that most of the adsorbed PA molecules have completely diffused into the interior of wool fiber.

From Figure 10c, a porous and fragile char was observed for the untreated wool due to the complete burning and insufficient char formation during the combustion. A series of voids are possibly caused by the volatiles which inflate the char. In the case of the treated wool, during the combustion, the original fiber structure was destroyed, but PA led to the formation of some additional fibrous chars which were not seen in the control sample. These observations indicate that the rate of char oxidation was decreased due to the presence of PA, and the char was much more complex [13]. In addition, unbroken intumescent-like bubbles were also found on the char residues of the treated wool fibers. These intumescent-like bubbles can hide combustible or volatile gases, slow down the heat transfer between gas and condensed phases, and prevent the underlying polymeric substrate from further attack by heat flux in a flame [38,39], resulting in the good FR performance of the treated wool fabric. 


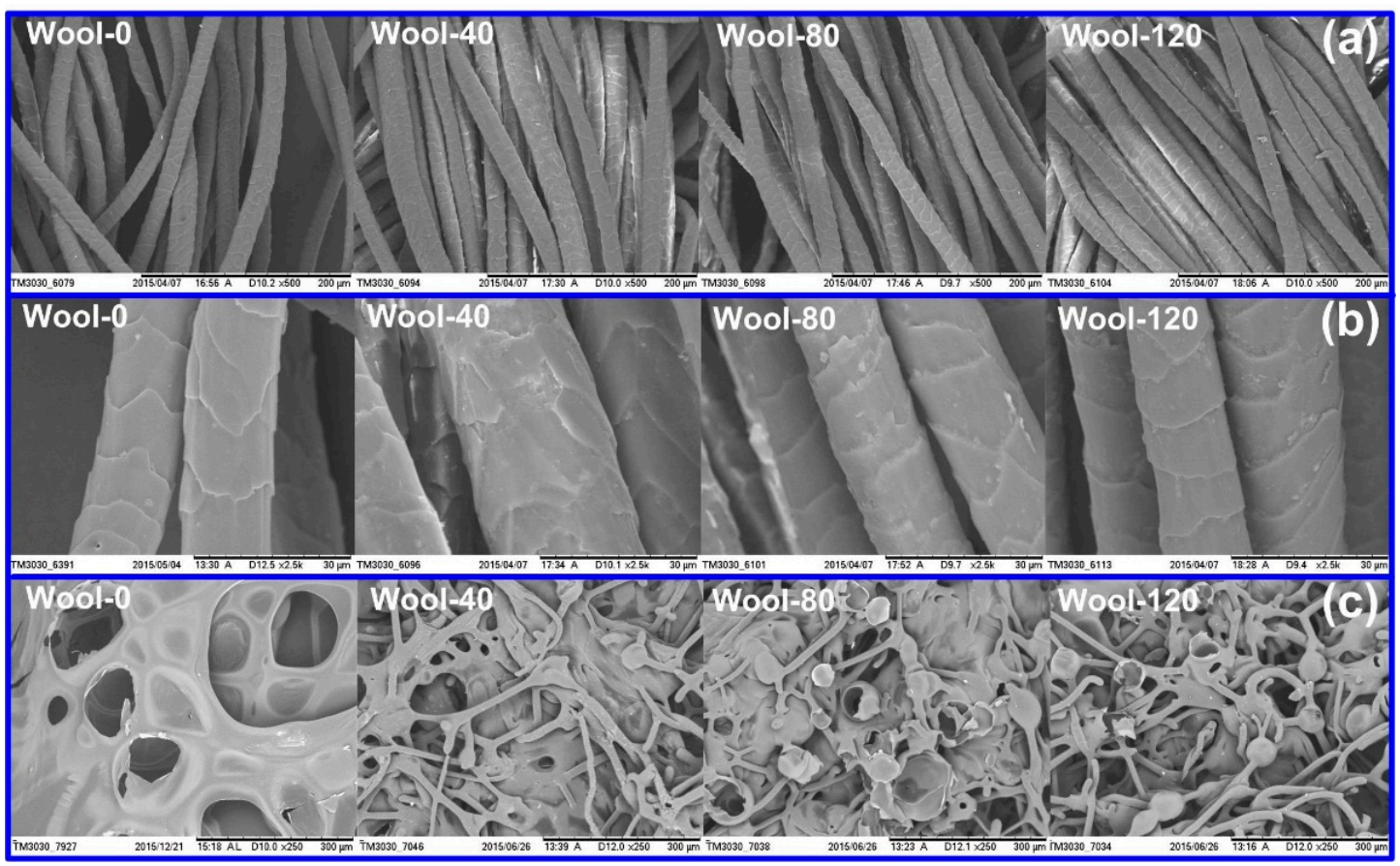

Figure 10. SEM micrographs of wool fibers $(\mathbf{a}, \mathbf{b})$ and char residues $(\mathbf{c})$.

\subsubsection{P Content Determination}

The total P content of the treated wool fibers and corresponding char residues was determined by ICP-OES, and the relative data are shown in Figure 11. The P content of the wool fibers and char residues increased with increasing PA concentration. Obviously, the P content of the char residues was much higher than that of the wool fibers. In addition, SEM-EDS was also used to evaluate the content of element $\mathrm{P}$ on the surface of the treated wool fibers and the residues after the PCFC test. The SEM-EDS results of the wool fabric treated by $120 \%$ owf PA and the corresponding char residue are depicted in Figure 12. From Figure 13, it is clear that the P content of the wool fiber surface increased with increasing PA concentration. The P content of the unburned Wool-40, Wool- 80 and Wool- 120 was $2.38,2.97$ and $3.13 \mathrm{wt} \%$, respectively, while that of the corresponding char residues was 5.88, 7.96 and $10.16 \mathrm{wt} \%$, respectively. These results indicate that the element $P$ participates in the formation of the char layer, which hinders the transfer of heat flow and combustible gas and thus provides good flame retardancy. Therefore, it can be concluded that the condensed-phase mechanism is applicable to the FR wool fabric treated with PA.

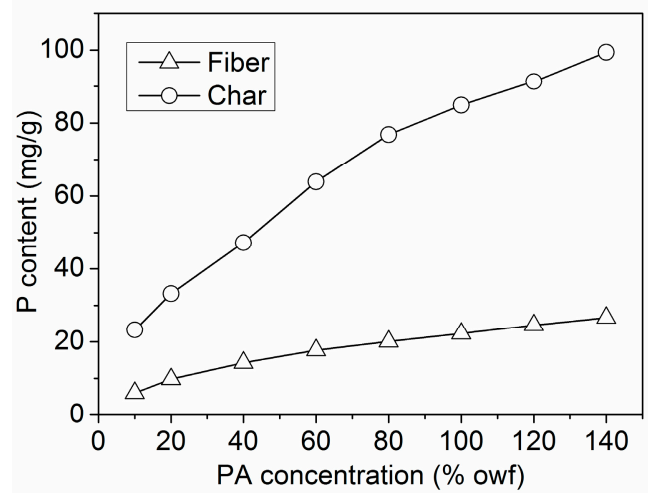

Figure 11. P content of wool fibers and corresponding char residues determined using ICP-OES. 


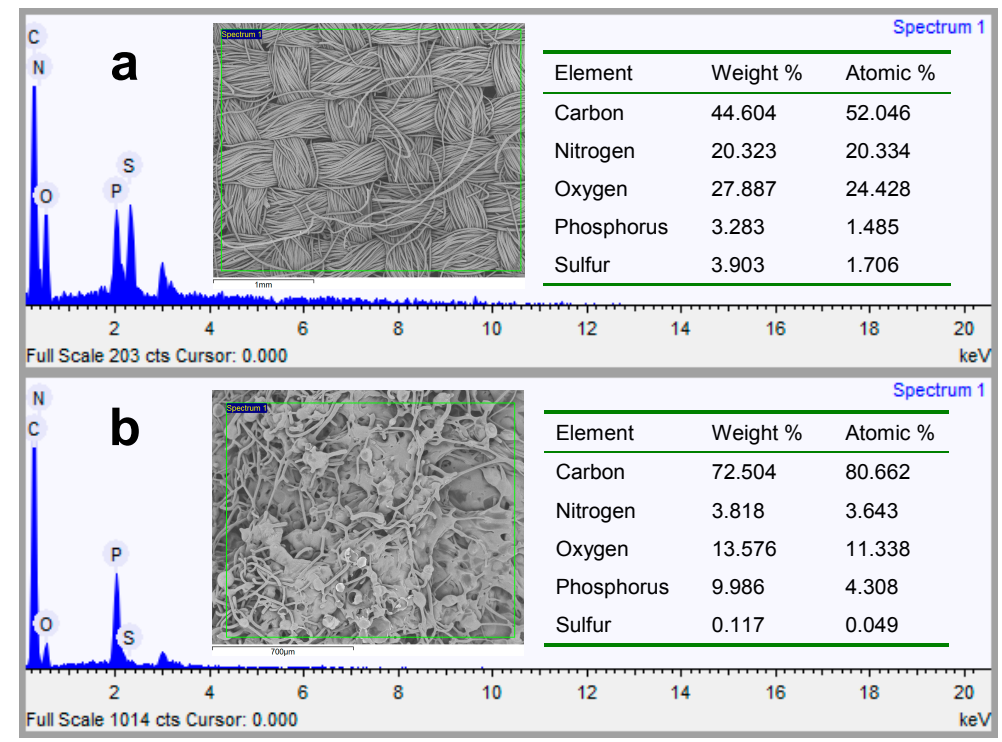

Figure 12. SEM-EDS micrographs of wool fiber (a) and char residue (b).

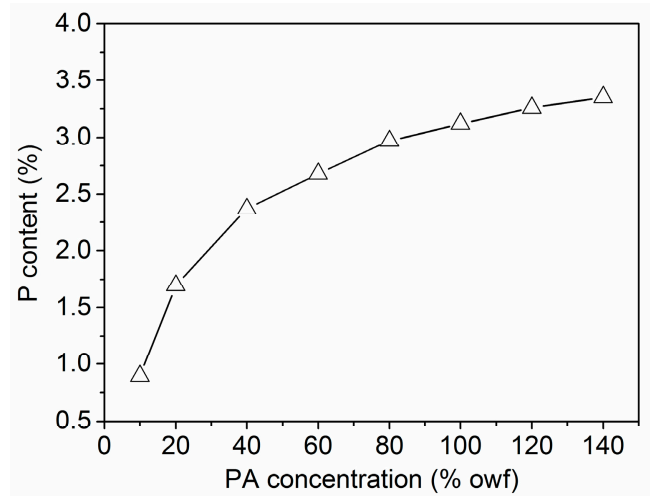

Figure 13. P content of wool fibers determined using SEM-EDS.

\subsection{Physical Properties}

\subsubsection{Whiteness Index}

The whiteness indexes of wool fabrics are shown in Figure 14. It can be observed that the application of PA reduced the whiteness of the fabrics, and the whiteness indexes decreased with increasing PA concentration. PA used in the present study is a slightly yellow solution, and the inherent yellow color of PA may induce the yellowing of wool fabrics. In addition, the oxidation yellowing of PA under heating [40] as well as the hydrolysis of the peptide chains of wool fiber at a low $\mathrm{pH}$ used in the PA treatment can also contribute to the yellowing of wool fabrics. 


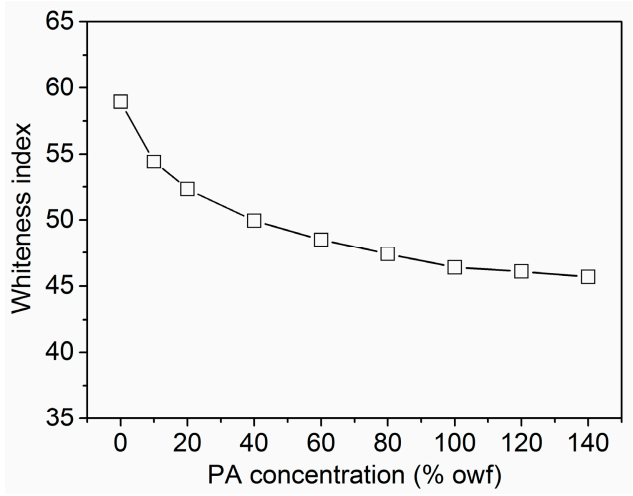

Figure 14. Whiteness of the wool fabrics treated with PA.

\subsubsection{Mechanical Performance}

The tensile strength of the treated wool fabric was compared to that of the untreated wool fabric to see whether PA has any adverse effect on mechanical performance. Tensile strength evaluation was obtained by measuring the maximum stress of stress-strain plot when the fabric starts to break. The stress-strain plots representing average values are shown in Figure 15. PA could combine with the wool fiber, and hydrolyze the amide linkage of the peptide chains at a low $\mathrm{pH}$. This means the treated wool (Wool-120) had a loss of tensile strength and elongation at break compared to the untreated wool. The original fabric had a mean tensile strength of $245.9 \pm 1.0 \mathrm{~N}$ and elongation of $22.1 \% \pm 1.1 \%$ at break, whereas the mean tensile strength and elongation of the treated fabric were $237.4 \pm 3.6 \mathrm{~N}$ and $21.0 \% \pm 1.8 \%$, respectively. PA treatment produced slightly decreased strength and elongation. Such a small decrease can be acceptable in the wet processing of wool fabric.

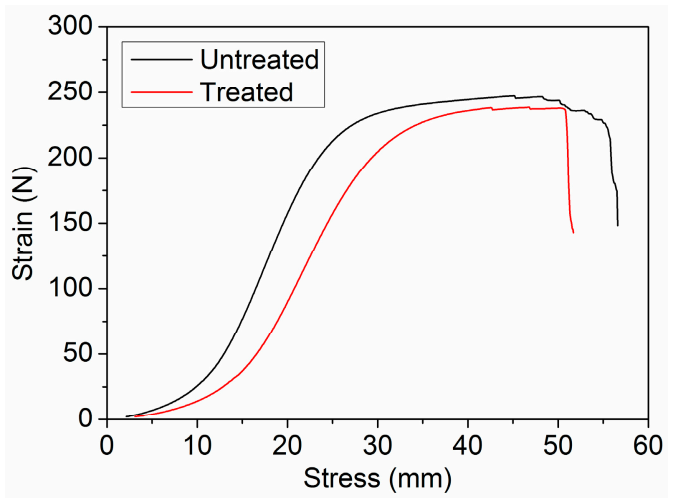

Figure 15. Stress-strain curves of the untreated and treated wool fabrics.

\subsection{Durability of FR Effect}

The washing resistance of the FR effect of textiles is directly related to the applicability of the corresponding products. Based on this, the treated fabric (Wool-120) was subjected to washing for different times. The result is shown in Figure 16. The FR performance of the treated fabric expressed by the LOI value decreased with increasing washing duration due to the water solubility of PA. However, PA can combine with wool fiber due to the electrostatic interaction between the positively charged amino groups in wool and the negatively charged phosphate groups in PA. Consequently, the LOI value of the treated fabric was still higher than $27.0 \%$ after laundering for $100 \mathrm{~min}$. All the same, special measures should be taken to improve the wash resistance of the FR wool fabrics in the future work. 


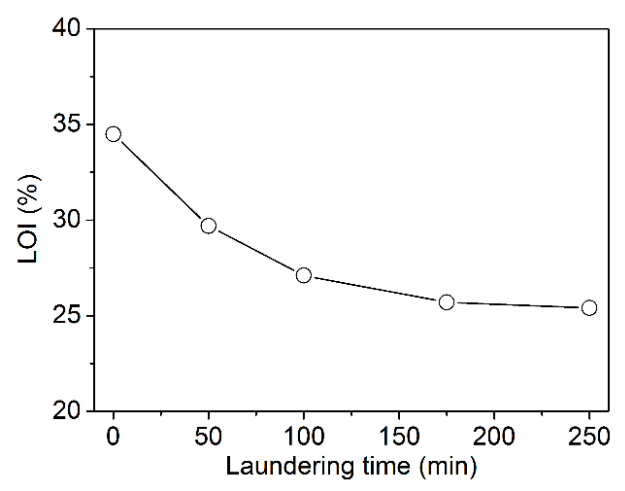

Figure 16. LOI of the treated wool fabric after laundering.

\section{Conclusions}

In the previous studies, PA as an anionic compound together with several cationic compounds containing silicon or nitrogen was used to improve the FR performance of cellulose-based materials. In this study, PA acted as an individual FR agent and was successfully applied to improve the FR properties of wool fabric using an exhaustion technique. The equilibrium adsorption isotherm of PA on wool could be described by the Langmuir model due to the electrostatic interactions between PA and wool fiber. The flame retardancy of the treated wool fabrics was confirmed by the results from the LOI, vertical burning and PCFC tests. PA has been proven to be a potential FR agent because of its high char-forming ability. The P content of the treated wool fibers was much lower than that of the corresponding char residues, indicating that $\mathrm{P}$ participates in the formation of the char layer, and the condensed-phase mechanism is suitable for FR wool fabrics. The use of PA provides an opportunity for producing FR wool fabrics using a green FR agent. In future work, some measures should be taken to improve the wash resistance of FR wool fabrics.

Acknowledgments: This study was funded by the Jiangsu Provincial Key Research and Development Program of China (BE2015066) and the Priority Academic Program Development (PAPD) of Jiangsu Higher Education Institutions.

Author Contributions: Xu-Hong Yang and Ren-Cheng Tang proposed and supervised the work. Xian-Wei Cheng performed the experiments, analyzed the data and wrote the manuscript. Jin-Ping Guan provided significant guidance on the flame-retardant mechanism. Guoqiang Chen provided lots of constructive suggestions about the work. Xu-Hong Yang and Ren-Cheng Tang revised the manuscript.

Conflicts of Interest: The authors declare no conflict of interest.

\section{Abbreviations}

The following abbreviations are used in this manuscript:

DTG Derivative Theremogravimetric

EDS Energy Dispersive X-ray Spectroscopy

FR Flame Retardant

FT-IR Fourier Transform Infrared

ICP-OES Inductively Coupled Plasma Optical Emission Spectrometry

LOI Limiting Oxygen Index

PCFC Pyrolysis Combustion Flow Calorimetry

PA Phytic Acid

SEM Scanning Electron Microscopy

TG Thermogravimetry 


\section{References}

1. Cardamone, J.M. Flame resistant wool and wool blends. In Handbook of Fire Resistant Textiles, 1st ed.; Selcen Kilinc, F., Ed.; Woodhead Publishing Limited: Cambridge, 2013; pp. 245-271.

2. Forouharshad, M.; Montazer, M.; Moghaddam, M.B.; Saligheh, O.; Roudbari, B.Y. Optimization of zirconium acetate on the flame retardant properties of wool. J. Appl. Polym. Sci. 2012, 125, 1261-1266. [CrossRef]

3. Flambard, X.; Bourbigot, S.; Kozlowski, R.; Muzyczek, M.; Mieleniak, B.; Ferreira, M.; Vermeulen, B.; Poutch, F. Progress in safety, flame retardant textiles and flexible fire barriers for seats in transportation. Polym. Degrad. Stabil. 2005, 88, 98-105. [CrossRef]

4. Benisek, L. Use of titanium complexes to improve natural flame retardancy of wool. J. Soc. Dyers Color. 1971, 87, 277-278.

5. Benisek, L. Improvement of the natural flame retardants of wool part I: Metal-Complex applications. J. Text. Inst. 1974, 65, 102-108. [CrossRef]

6. Martini, P.; Spearpoint, M.J.; Ingham, P.E. Low-cost wool-based fire blocking inter-liners for upholstered furniture. Fire. Saf. J. 2010, 45, 238-248. [CrossRef]

7. Moghadam, M.B. A comparative optimization study of flame retardancy of wool fabric with and without robust parameter design approach. World Appl. Sci. J. 2011, 13, 2252-2257.

8. Forouharshad, M.; Montazer, M.; Moghadam, M.B.; Saligheh, O. Flame retardancy of wool fabric with zirconium oxychloride optimized by central composite design. J. Fire Sci. 2010, 28, 561-572. [CrossRef]

9. Forouharshad, M.; Montazer, M.; Moghadam, M.B.; Saligheh, O. Preparation of flame retardant wool using zirconium acetate optimized by CCD. Thermochim. Acta 2011, 520, 134-138. [CrossRef]

10. Tian, C.M.; Li, Z.; Guo, H.Z.; Xu, J.Z. Study on the thermal degradation of flame retardant wools. J. Fire Sci. 2003, 21, 155-162. [CrossRef]

11. Horrocks, A.R. Flame-retardant finishing of textile. Rev. Prog. Color. 1986, 16, 62-101. [CrossRef]

12. Horrocks, A.R.; Davies, P.J. Char formation in flame-retarded wool fibres. Part 1. Effect of intumescent on thermogravimetric behaviour. Fire. Mater. 2000, 24, 151-157. [CrossRef]

13. Davies, P.J.; Horrocks, A.R.; Miraftab, M. Scanning electron microscopic studies of wool/intumescent char formation. Polym. Int. 2000, 49, 1125-1132. [CrossRef]

14. Tian, C.M.; Zhang, H.Y.; Xu, J.Z.; Gua, H.Z.; Shi, J.R. Studies on the flame retardation and thermal degradation of wool. J. Text. Inst. 1998, 89, 591-594. [CrossRef]

15. Gashti, M.P.; Almasian, A.; Gashti, M.P. Preparation of electromagnetic reflective wool using nano- $\mathrm{ZrO}_{2}$ /citric acid as inorganic/organic hybrid coating. Sens. Actuat. A 2012, 187, 1-9.

16. Malucelli, G.; Bosco, F.; Alongi, J.; Carosio, F.; Di Blasio, A.; Mollea, C.; Cuttica, F.; Casale, A. Biomacromolecules as novel green flame retardant systems for textiles: An overview. RSC Adv. 2014, 4, 46024-46039. [CrossRef]

17. Alongi, J.; Carletto, R.A.; Bosco, F.; Carosio, F.; Di Blasio, A.; Cuttica, F.; Antonucci, V.; Giordano, M.; Malucelli, G. Caseins and hydrophobins as novel green flame retardants for cotton fabrics. Polym. Degrad. Stabil. 2014, 99, 111-117. [CrossRef]

18. Bosco, F.; Carletto, R.A.; Alongi, J.; Marmo, L.; Di Blasio, A.; Malucelli, G. Thermal stability and flame resistance of cotton fabrics treated with whey proteins. Carbohyd. Polym. 2013, 94, 372-377. [CrossRef] [PubMed]

19. Alongi, J.; Carletto, R.A.; Di Blasio, A.; Carosio, F.; Bosco, F.; Malucelli, G. DNA: A novel, green, natural flame retardant and suppressant for cotton. J. Mater. Chem. A 2013, 1, 4779-4785. [CrossRef]

20. Alongi, J.; Carletto, R.A.; Di Blasio, A.; Cuttica, F.; Carosio, F.; Bosco, F.; Malucelli, G. Intrinsic intumescent-like flame retardant properties of DNA-treated cotton fabrics. Carbohyd. Polym. 2013, 96, 296-304. [CrossRef] [PubMed]

21. Carosio, F.; Di Blasio, A.; Cuttica, F.; Alongi, J.; Malucelli, G. Flame retardancy of polyester and polyester-cotton blends treated with caseins. Ind. Eng. Chem. Res. 2014, 53, 3917-3923. [CrossRef]

22. Duskovar, D.; Marounek, M.; Brezina, P. Determination of phytic acid in feeds and faeces of pigs and poultry by capillary isotachophoresis. J. Sci. Food Agric. 2000, 81, 36-41.

23. Moccelini, S.K.; Fernandes, S.C.; Vieira, I.C. Bean sprout peroxidase biosensor based on L-cysteine self-assembled monolayer for the determination of dopamine. Sensor. Actuat. B Chem. 2008, 133, 364-369. [CrossRef] 
24. Jo, S.; Jeong, H.; Bae, S.R.; Jeon, S. Modified platinum electrode with phytic acid and single-walled carbon nanotube: Application to the selective determination of dopamine in the presence of ascorbic and uric acids. Microchem. J. 2008, 88, 1-6. [CrossRef]

25. Ye, C.H.; Zheng, Y.F.; Wang, S.Q.; Xi, T.F.; Li, Y.D. In vitro corrosion and biocompatibility study of phytic acid modified WE43 magnesium alloy. Appl. Surf. Sci. 2012, 258, 3420-3427. [CrossRef]

26. Laufer, G.; Kirkland, C.; Morgan, A.B.; Grunlan, J.C. Intumescent multilayer nanocoating, made with renewable polyelectrolytes, for flame-retardant cotton. Biomacromolecules 2012, 13, 2843-2848. [CrossRef] [PubMed]

27. Zhou, Y.; Ding, C.; Qian, X.; An, X. Further improvement of flame retardancy of polyaniline-deposited paper composite through using phytic acid as dopant or co-dopant. Carbohyd. Polym. 2015, 115, 670-676. [CrossRef] [PubMed]

28. Wang, X.; Romero, M.Q.; Zhang, X.-Q.; Wang, R.; Wang, D.-Y. Intumescent multilayer hybrid coating for flame retardant cotton fabrics based on layer-by-layer assembly and sol-gel process. RSC Adv. 2015, 5, 10647-10655. [CrossRef]

29. Costes, L.; Laoutid, F.; Dumazert, L.; Lopez-cuesta, J.M.; Brohez, S.; Delvosalle, C.; Dubois, P. Metallic phytates as efficient bio-based phosphorous flame retardant additives for poly (lactic acid). Polym. Degrad. Stabil. 2015, 119, 217-227. [CrossRef]

30. Yang, L.Z.; Liu, H.Y.; Hu, N.F. Assembly of electroactive layer-by-layer films of myoglobin and small-molecular phytic acid. Electrochem. Commun. 2007, 9, 1057-1061. [CrossRef]

31. Chen, Y.; Zhao, S.; Liu, B.; Chen, M.; Mao, J.; He, H.; Zhao, Y.; Huang, N.; Wan, G. Corrosion-Controlling and Osteo-Compatible Mg Ion-Integrated Phytic Acid (Mg-PA) Coating on Magnesium Substrate for Biodegradable Implants Application. ACS Appl. Mater. Interfaces 2014, 6, 19531-19543. [CrossRef] [PubMed]

32. Schartel, B.; Pawlowski, K.H.; Lyon, R.E. Pyrolysis combustion flow calorimeter: A tool to assess flame retarded PC/ABS materials? Thermochim. Acta 2007, 462, 1-14. [CrossRef]

33. Lyon, R.E.; Walters, R.N.; Stoliarov, S.I. Screening flame retardants for plastics using microscale combustion calorimetry. Polym. Eng. Sci. 2007, 47, 1501-1510. [CrossRef]

34. Razmjooei, F.; Singh, K.P.; Bae, E.J.; Yu, J.-S. A new class of electroactive Fe- and P- functionalized graphene for oxygen reduction. J. Mater. Chem. A 2015, 3, 11031-11039. [CrossRef]

35. Jiang, G.; Qiao, J.; Hong, F. Application of phosphoric acid and phytic acid-doped bacterial cellulose as novel proton-conducting membranes to PEMFC. Int. J. Hydrogen. Energ. 2012, 37, 9182-9192. [CrossRef]

36. Guo, X.; Miao, Y.; Ye, P.; Wen, Y.; Yang, H. Multi-walled carbon nanotubes in aqueous phytic acid for enhancing biosensor. Mater. Res. Express 2014, 1, 025403. [CrossRef]

37. Carran, R.S.; Ghosh, A.; Dyer, J.M. The effects of zeolite molecular sieve based surface treatments on the properties of wool fabrics. Appl. Surf. Sci. 2013, 287, 467-472. [CrossRef]

38. Carosio, F.; Alongi, J.; Malucelli, G. Flammability and combustion properties of ammonium polyphosphate-/poly(acrylic acid)-based layer by layer architectures deposited on cotton, polyester and their blends. Polym. Degrad. Stabil. 2013, 98, 1626-1637. [CrossRef]

39. Zhang, R.; Xiao, X.; Tai, Q.; Huang, H.; Hu, Y. Modification of lignin and its application as char agent in intumescent flame-retardant poly (lactic acid). Polym. Eng. Sci. 2012, 52, 2620-2626. [CrossRef]

40. Daneluti, A.L.M.; Matos, J.D.R. Study of thermal behavior of phytic acid. Braz. J. Pharm. Sci. 2013, 49, 275-283. [CrossRef]

(C) 2016 by the authors; licensee MDPI, Basel, Switzerland. This article is an open access article distributed under the terms and conditions of the Creative Commons by Attribution (CC-BY) license (http:/ / creativecommons.org/licenses/by/4.0/). 